\title{
Evaluating and optimizing oral formulations of live bacterial vaccines using a gastro-small intestine model
}

Article

Accepted Version

Creative Commons: Attribution-Noncommercial-No Derivative Works 4.0

de Barros, J. M.S., Costabile, A., Charalampopoulos, D. ORCID: https://orcid.org/0000-0003-1269-8402, Khutoryanskiy, V. V. and Edwards, A. D. (2016) Evaluating and optimizing oral formulations of live bacterial vaccines using a gastro-small intestine model. European Journal of

Pharmaceutics and Biopharmaceutics, 102. pp. 115-122. ISSN 0939-6411 doi: https://doi.org/10.1016/j.ejpb.2016.03.010 Available at https://centaur.reading.ac.uk/58447/

It is advisable to refer to the publisher's version if you intend to cite from the work. See Guidance on citing.

Published version at: http://dx.doi.org/10.1016/j.ejpb.2016.03.010

To link to this article DOI: http://dx.doi.org/10.1016/j.ejpb.2016.03.010

Publisher: Elsevier

All outputs in CentAUR are protected by Intellectual Property Rights law, including copyright law. Copyright and IPR is retained by the creators or other copyright holders. Terms and conditions for use of this material are defined in the End User Agreement. 


\section{CentAUR}

Central Archive at the University of Reading

Reading's research outputs online 


\title{
Evaluating and Optimizing Oral Formulations of Live Bacterial Vaccines Using a Gastro-Small Intestine Model
}

\author{
João M. S. de Barros ${ }^{1}$, Adele Costabile ${ }^{2,3}$, Dimitrios Charalampopoulos ${ }^{2}$, \\ Vitaliy V. Khutoryanskiy ${ }^{1}$ and Alexander D. Edwards ${ }^{1} *$ \\ ${ }^{1}$ School of Pharmacy, University of Reading, Whiteknights, Reading RG6 6AD, UK. \\ ${ }^{2}$ Food and Nutritional Sciences, University of Reading, Whiteknights, Reading RG6 6AD, UK. \\ ${ }^{3}$ Current address: Health Sciences Research Centre, University of Roehampton, SW15 4JD, UK. \\ * Corresponding author contact details. Email: a.d.edwards@ reading.ac.uk. Phone <44> 1183784253 \\ Fax +44 (0) 1183784703 .
}

\begin{abstract}
.
Gastrointestinal (GI) models that mimic physiological conditions in vitro are important tools for developing and optimizing biopharmaceutical formulations. Oral administration of live attenuated bacterial vaccines (LBV) can safely and effectively promote mucosal immunity but new formulations are required that provide controlled release of optimal numbers of viable bacterial cells, which must survive gastrointestinal transit overcoming various antimicrobial barriers. Here, we use a gastro-small intestine gut model of human GI conditions to study the survival and release kinetics of two oral LBV formulations: the licensed typhoid fever vaccine Vivotif comprising enteric coated capsules; and an experimental formulation of the model vaccine Salmonella Typhimurium SL3261 dried directly onto cast enteric polymer films and laminated to form a polymer film laminate (PFL). Neither formulation released significant numbers of viable cells when tested in the complete gastro-small intestine model. The poor performance in delivering viable cells could be attributed to a combination of acid and bile toxicity plus incomplete release of cells for Vivotif capsules, and to bile toxicity alone for PFL. To achieve effective protection from intestinal bile in addition to effective acid resistance, bile adsorbent resins were incorporated into the PFL to produce a new formulation, termed BR-PFL. Efficient and complete release of $4.4 \times 10^{7}$ live cells per dose was achieved from BR-PFL at distal intestinal $\mathrm{pH}$, with release kinetics controlled by the composition of the enteric polymer film, and no loss in viability observed in any stage of the GI model. Use of this in vitro GI model thereby allowed rational design of an oral LBV formulation to maximize viable cell release.
\end{abstract}

\section{KEYWORDS}

In vitro modeling; oral administration; enteric delivery; live bacterial vaccines; polymer film

\section{ABBREVIATIONS}

LBV, live bacterial vaccine; GI, gastro-intestinal; SIF, USP simulated intestinal fluid (pH 7.0); SGF, USP simulated gastric fluid ( $\mathrm{pH}$ 2.0); BioSGF, complete simulated gastric fluid; BioSIF, complete 
simulated intestinal fluid; CFU, colony forming unit; PFL, polymer film laminate; BR-PFL, bile resin polymer film laminate.

\section{Introduction}

Live bacterial cells are administered orally as attenuated vaccines [1], for in situ production of biopharmaceuticals [2], or as probiotics to improve gastrointestinal (GI) health [3]. Attenuated live bacterial vaccines (LBV) administered orally (e.g. Vivotif, CholeraGarde), closely mimic natural infection and promote potent, long-lasting protective immunity [1]. The small intestine mucosa, particularly the Peyer's patches found in the ileum, is typically the target site for oral LBV. Although many formulations have been developed for oral delivery of therapeutic live bacteria ranging from exotic functional foods to yoghurt [4], solid dosage forms such as capsules or tablets containing dried live bacteria offer the most control of both dose and site of delivery whilst drying is essential to achieve stability and shelf life [5]. However, even in late stage clinical trials LBV are still being administered in bicarbonate buffer suspension reconstituted from lyophilized stocks (e.g. attenuated cholera strains Peru-15 [6] and CVD 103-HgR [7]) - a formulation that did not gain large scale adoption for Ty21a in spite of the greater immunogenicity of buffered liquid administration over capsules in clinical trials [8, 9]. The poor palatability of bicarbonate buffers has led to the suggestion of alternate liquid formulations such as protein shakes [10] which provide effective protection of attenuated vaccine cells from gastric acid.

Like other biopharmaceuticals, LBV present unique formulation challenges not only during manufacture but also after administration, and dried bacterial cells must survive many antimicrobial defenses during GI transit including gastric acid, antimicrobial, gastric and pancreatic enzymes, and bile surfactants. Although non-viable bacterial cells can promote immunity, viable cells are significantly more immunogenic [11]. These challenges are exacerbated by an elevated sensitivity to acid and bile when dried [12-14]. Acid-labile conventional pharmaceuticals are protected from gastric acid by encapsulation using gastro-resistant coatings such as acid-insoluble enteric polymers [15-17], and Vivotif is formulated in a capsule coated with hydroxypropymethylcellulose- phthalate. In contrast live bacterial vaccines in recent clinical trials utilize an unconventional oral delivery form, with lyophilized cells resuspended in a bicarbonate buffer in an effort to neutralize gastric acid following oral administration (e.g. [6]). Delivery to the intestine using enteric coatings releases tablet or capsule content to intestinal microbicides including bile. Although the main function of bile acids is to solubilise dietary lipids, many microbes are intolerant to detergents and bile represents a major microbicidal barrier to the survival of bacteria in the gut. Drying even highly bile adapted enteric organisms such as Salmonella bacteria increases susceptibility to bile, raising the possibility that, but dry cells released from enteric coated formulations may then be rapidly killed by bile following intestinal release, dramatically reducing dose of viable cells. This temporary bile sensitivity of dried cells is rapidly reversed after rehydration and bile adsorbing resins can be added to oral formulations to protect dried cells from bile toxicity [12-14].

Understanding the fate of food and drugs after ingestion is both vital to achieve efficient delivery and uptake of pharmaceuticals and to understand the impact of diet on gut health, and in vitro modelling remains a critical tool for study of food and oral formulations in the GI tract. In vivo studies 
are complex and expensive and although critical to understand vaccine efficacy, have not been used to assess the delivery of live bacterial vaccine cells; instead, preclinical studies focus on immunogenicity as a downstream consequence of administration of formulated cells. In some studies fecal shedding can be monitored as an indirect indicator of GI bacterial load but immune responses can be generated without fecal shedding proving this is a poor indicator of live cell delivery. Small animal models cannot be used to test human dosage forms as capsules and tablets are too large for oral administration, and there are no published reports of the release kinetics and location or number of viable cells released into the GI tract of large monogastric mammals from solid oral formulations of therapeutic live cells. As a result we know very little about the fate of live therapeutic cells administered orally, or the influence of cell viability and release location on downstream immunogenicity, and so carefully designed in vitro studies remain vital.

Conventional dissolution testing utilizes very simple simulated GI fluids, typically a simple acidic simulated gastric fluid (SGF; often $0.1 \mathrm{M} \mathrm{HCl}, \mathrm{pH} \sim 2.0$ ) followed by a simple phosphate buffer for simulated intestinal fluid (SIF; typically $\mathrm{pH}$ 6.8) to simulate intestinal transit, with some minor variations such as the $\mathrm{pH}$ or the addition of enzymes [18]. Although carefully defined simple dissolution testing protocols are adequate for testing small molecule drugs and essential for manufacturing quality control, these conditions poorly reflect the dynamic and complex physiological conditions encountered during GI transit in vivo. Simple SGF and SIF are particularly inappropriate for complex biological therapeutics such as live therapeutic bacteria since they lack antimicrobial components such as bile acids. Several validated gastrointestinal models have been developed [19] such as the three-stage compound continuous culture system that simulates the nutritional and environmental conditions in the human large intestine [20]; TIM, a multi-compartmental, dynamic computer-controlled model that simulates the GI tract [21]; and the simulator of the human microbial ecosystem (SHIME) which operates in sequential batch mode and simulates the entire human gastrointestinal system [22]. Here, we adapted an established gut model designed and validated to reproduce the spatial, temporal, nutritional, and physicochemical characteristics of the microbiota in the human colon [23] to the study of oral formulations of live bacterial vaccines. This three-stage continuous culture system comprises of three glass fermenters simulating the ascending, transverse, and distal colon, and contains a complete microbiota from a fecal inoculum.

In this study, upstream gastric and small intestinal stages were added to this model to study viability and release of LBV from oral formulations through simulated GI transit. We evaluated the fate of LBV for both an established licensed oral vaccine formulation in a enteric coated capsules (Vivotif), and a novel polymer film laminate formulation developed recently by our laboratory [17]. These formulations were previously tested in simple SGF and SGF but the effect of complete simulated gastrointestinal fluids that mimic physiological conditions has not been reported. We found that dried Salmonella typhi strain Ty21a cells in the enteric coated Vivotif capsules were sensitive to both gastric acid and bile, suggesting that major losses in viable cell numbers are likely to be released in vivo from this widely used vaccine formulation. Likewise, although our novel enteric polymer film laminate (PFL) formulation was effective at protecting live bacteria of a model vaccine strain of Salmonella typhimurium from gastric acid, dried cells in this formulation remained highly susceptible to bile. We therefore incorporated bile sequestrants into the polymer films to produce a bile resistant polymer film 
laminate (BR-PFL) formulation, which delivered maximal viable cells to the simulated distal intestinal site.

\section{Materials and methods}

Materials. Eudragit L100 55 (Eudragit L, methacrylic acid-ethyl acrylate copolymer 1:1), was provided from Evonik, Germany. Cholestyramine, triethyl citrate, sodium chloride, potassium phosphate buffer, pancreatin, pepsin, LB broth and LB agar were purchased from Sigma Aldrich (Gillingham, UK). Peptone and bile salts were from Oxoid (Basingstoke, UK). The oral typhoid fever vaccine Vivotif consisting of Salmonella Typhi strain Ty21a formulated in a capsule coated with hydroxypropymethylcellulose-phthalate, was from Crucell (Netherlands). The model live bacterial vaccine strain was Salmonella enterica serovar Typhimurium strain SL3261.

In vitro gastro-small intestine model system. A semi-continuous gastro-small intestine model system was constructed (Fig. 1) consisting of four (V1, V2, V3 and V4) jacketed glass vessels (Soham scientific, UK), with operating volumes of 50, 100, 100 and $100 \mathrm{~mL}$ representing the stomach, duodenum, jejunum and ileum, respectively. Each vessel was completely sealed and had a cover designed to accommodate a sample glass holder (design to keep PFL form in place without affecting dissolution), $\mathrm{pH}$ electrode, temperature probe, and entry parts for $\mathrm{N}_{2}, 0.5 \mathrm{M} \mathrm{HCl}, 0.5 \mathrm{M} \mathrm{NaOH}$, and digesta if necessary, and contents continuously mixed by magnetic stirrer bar. The temperature was maintained by circulating water at $37^{\circ} \mathrm{C}$ through the jacketed vessels. $\mathrm{pH}$ controller pumps (Fermac 260; Electrolab, Tewkesbury, United Kingdom) were used to automatically control the $\mathrm{pH}$ of the simulated fluid in vessels V2, V3 and V4 to $\mathrm{pH} 5.5,6.5$ and 7.2, respectively. An anaerobic environment was maintained by sparing all vessels with $\mathrm{O}_{2}$-free $\mathrm{N}_{2}(15 \mathrm{~mL} / \mathrm{min})$.

\section{Figure 1}

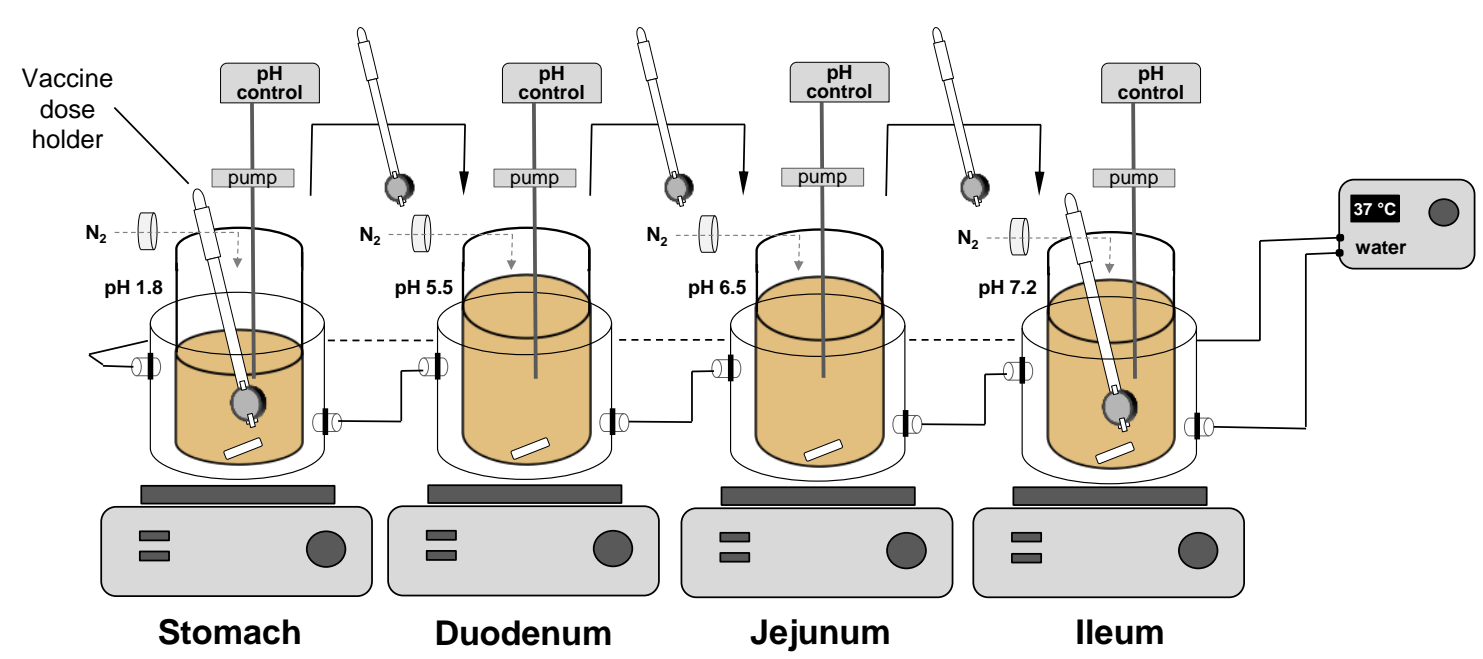

FIGURE 1. A gastro small intestine model to study live bacterial vaccine delivery from oral formulations in vitro. Schematic diagram of the semi-continuous four stage in vitro gastro-small intestine model used in this study. The system 
consists of four sequential vessels, V1 (50 mL, pH 1.8), V2 (100 mL pH 5.5), V3 (100 mL pH 6.5) and V4 (100 mL pH 7.2), representing the stomach, duodenum, jejunum and ileum respectively. In each vessel temperature $\left(37^{\circ} \mathrm{C}\right)$ and $\mathrm{pH}$ were automatically controlled, contents were magnetically stirred and maintained under anaerobic conditions. A single dose of each vaccine formulation was submerged sequentially in the four stages, with transit times in each compartment of 2 hours in V1, 5 min in V2, 25 min in V3 and 2.5 hours in V4. Samples were taken periodically and viable cell numbers counted by plating in replicate

Simulated gastro-intestinal fluids. Pharmacopeia standard simple simulated gastro-intestinal fluids (USP26 - SGF or SIF) and complex simulated human gastro-intestinal fluids (BioSGF or BioSIF) had the following composition. SGF was $0.1 \mathrm{M} \mathrm{HCl}$ at $\mathrm{pH} 2.0$. SIF was phosphate buffer at $0.68 \% \mathrm{w} / \mathrm{v}$ potassium dihydrogen phosphate at $\mathrm{pH} 6.8$ plus $1 \%$ peptone (adjusted with $0.2 \mathrm{M} \mathrm{NaOH}$ or $0.2 \mathrm{M}$ $\mathrm{HCl})$. BioSGF was $0.2 \% \mathrm{w} / \mathrm{v} \mathrm{NaCl}, 0.03 \% \mathrm{w} / \mathrm{v}$ bile salts and $0.3 \% \mathrm{w} / \mathrm{v}$ pepsin, adjusted with $1 \mathrm{M}$ $\mathrm{HCl}$ to $\mathrm{pH} 1.8$. BioSIF was $0.4 \% \mathrm{w} / \mathrm{v} \mathrm{NaCl}, 1.1 \% \mathrm{w} / \mathrm{v}$ bile salts, $1 \% \mathrm{w} / \mathrm{v}$ pancreatin, $0.4 \% \mathrm{w} / \mathrm{v}$ phosphate buffer $\mathrm{KH}_{2} \mathrm{PO}_{4}$ and $1 \%$ peptone adjusted with $0.5 \mathrm{M} \mathrm{HCl}$ or $0.5 \mathrm{M} \mathrm{NaOH}$ to pH 5.5 (duodenum), pH 6.5 (jejunum) and pH 7.2 (ileum), respectively. All solutions and growth media were sterilized by autoclaving except enzyme/bile solutions that were sterile filtered.

Preparation of polymer film laminate formulations (PFL) and Bile Resistant PFL. Polymer films were cast as described [17] from solutions of Eudragit L100 55 (12.5\% w/v) in ethanol with 25 $\%$ w/w triethyl citrate plasticizer added based on the polymer mass. Where indicated the bile adsorbant resin cholestyramine (10\% w/v) was added to Eudragit L100 $557.5 \%$ w/v. Polymer solutions were cast in $90 \mathrm{~mm}$ diameter Petri dishes with the volumes adjusted $(5-15 \mathrm{~mL})$ to achieve a dry film thickness ranging from $100 \mu \mathrm{m}$ to $200 \mu \mathrm{m}$. PFL - A was as previously described [17]. Novel bile resistant PFL (BR-PFL) were prepared as follows: BR-PFL B - 1 layer of Eudragit and cholestyramine; BR-PFL C 2 outer layer Eudragit alone, inner layer Eudragit + cholestyramine; BR-PFL D outer layer Eudragit alone, middle layer Eudragit + cholestyramine, inner layer Eudragit alone (3 layers). Each layer was dried at room temperature for $24 \mathrm{~h}$ before adding the next layer. Thick Eudragit films (up to 1 $\mathrm{mm}$ ) were used to make spacers between laminated dried cell spots. Thermogravimetric analysis confirmed complete solvent removal to prevent toxicity. Prior to adding bacteria, films were sterilized by UV irradiation and handled aseptically. SL3261 cells were dried onto polymer films in $40 \% \mathrm{w} / \mathrm{v}$ trehalose in a desiccator at $20^{\circ} \mathrm{C}$ for a minimum of 18 hours, with relative humidity remaining between 4- $6 \%$ and temperature within $\pm 1^{\circ} \mathrm{C}$ monitored by USB datalogger (Omega, UK) and laminated together as previously described [17]. Prototype BR-PFL formulations were either tested directly in simulated intestinal fluids, or pre-incubated in simulated gastric fluid (SGF or BioSGF) (pH 1.8, 50 $\mathrm{mL}$ ) at $37^{\circ} \mathrm{C}$ for 2 hours in beakers with orbital shaking at $100 \mathrm{rpm}$, and compared to control PFL formulations. By visual inspection all formulations remained intact in gastric fluid, although samples were checked for live cell release. Formulations were transferred into $100 \mathrm{~mL}$ simulated intestinal fluid (SIF or BioSIF) at $\mathrm{pH} 7.2$ and $37^{\circ} \mathrm{C}$ and live cell release was determined at $0,1,2$ and $3 \mathrm{~h}$.

Viable cell counting. Cell viability was evaluated using serial dilution of samples and agar plate colony counting. $5 \mu \mathrm{L}$ samples of serial 3-fold dilutions were plated as spots onto LB agar. Colonies were counted after overnight incubation on spots with 5-30 colonies, and final viability calculated and presented as colony forming unit per $\mathrm{mL}(\mathrm{CFU} / \mathrm{mL})$, per capsule for Vivotif tests (CFU/capsule), or per $\mathrm{mg}$ dry cell powder (CFU/mg) depending on the sample tested. To compare viablity post-drying vs 
after GI testing, cell counts were expressed relative to the initial volume of the cell slurry before drying for PFL.

Survival and cell release from encapsulated oral formulations. Complete formulations were tested in the gastro-small intestine model system which was anaerobic, $\mathrm{pH}$ controlled, water jacketed and magnetically stirred. In some experiments, where indicated, formulations and dried cell samples were testing in beakers under aerobic, $\mathrm{pH}$ pre-adjusted, with orbital shaking in an incubator. The formulations were placed first into SGF or BioSGF (50 mL, pH 1.8, stomach) and incubated $\left(37{ }^{\circ} \mathrm{C}, 2\right.$ $\mathrm{h}$, orbital shaking at $100 \mathrm{rpm}$ or magnetic stirred); a sample was taken at $2 \mathrm{~h}$ to determine live cell numbers. After, the formulation was transferred into SIF or BioSiF $(\mathrm{pH} 5.5,100 \mathrm{~mL}$, simulating duodenum) and incubated $\left(37^{\circ} \mathrm{C}, 5 \mathrm{~min}\right.$, orbital shaking at $100 \mathrm{rpm}$ or magnetically stirred), then into SIF or BioSIF (pH 6.5, $100 \mathrm{~mL}$, simulating jejunum) and incubated $\left(37^{\circ} \mathrm{C}, 25 \mathrm{~min}\right.$, orbital shaking at $100 \mathrm{rpm}$ or magnetically stirred), and finally, the formulations were placed into SIF or BioSIF (pH 7.2, $100 \mathrm{~mL}$, simulating Ileum) and incubated $\left(37^{\circ} \mathrm{C}, 24 \mathrm{~h}\right.$, orbital shaking at $100 \mathrm{rpm}$ or magnetic stirred). In the simulated stomach, duodenum and jejunum, a sample was taken just before removing the formulation to determine live cell numbers. In the virtual ileum the cells were counted at $1 \mathrm{~h}, 2.5 \mathrm{~h}$ and $24 \mathrm{~h}$. For each experiment, a replicate formulation was placed in LB broth or SIF+peptone (10 $\mathrm{mL})$ and incubated at $37^{\circ} \mathrm{C}$ for $60 \mathrm{~min}$, with shaking at $100 \mathrm{rpm}$, and cells counted to determine the total viable cell number per formulation for comparison.

Protection of Vivotif formulation from bile and acid. Vivotif enteric-coated capsules (Crucell) were placed either in SGF or BioSGF (50 mL, pH 1.8, stomach) and incubated $\left(37^{\circ} \mathrm{C}, 2 \mathrm{~h}\right.$, orbital shaking); a sample was taken at $2 \mathrm{~h}$ to determine live cell numbers. After $2 \mathrm{~h}$, the formulation was transferred into SIF or BioSiF (pH 7.2, $100 \mathrm{~mL})$ and incubated $\left(37^{\circ} \mathrm{C}, 3 \mathrm{~h}\right.$, orbital shaking at $\left.100 \mathrm{rpm}\right)$ with live cells counted after $3 \mathrm{~h}$. Vivotif capsules were also aseptically opened and 10mg samples of dried cell powder placed into culture medium, SIF or BioSiF (pH 7.2, $100 \mathrm{~mL}$ ) at $37{ }^{\circ} \mathrm{C}, 3 \mathrm{~h}$, with orbital shaking, with live cell numbers measured at $3 \mathrm{~h}$. To determine toxicity of the gastric stage, formulations were also placed directly into simulated intestinal fluids. To test the intrinsic bile sensitivity of Salmonella Typhi Ty21 after rehydration in culture medium, individually weighed samples of approximately $10 \mathrm{mg}$ were placed in $50 \mathrm{~mL}$ tubes, and $10 \mathrm{~mL}$ of growth medium (LB broth) or SIF with or without $1 \%$ bile were added, followed by incubation at $37^{\circ} \mathrm{C}$ and sampling live cell numbers at one hour. These were compared to Vivotif powder that was firstly rehydrated in $10 \mathrm{~mL}$ growth medium without bile for 0.5 hours then $2 \%$ bile added to provide a final concentration of $1 \% \mathrm{w} / \mathrm{v}$.

\section{Statistical analysis}

All data were analysed by one-way ANOVA, using Tukey post-hoc test analysis when the overall $\mathrm{P}$ value of the experiment was below the value of significance $(\mathrm{P}<0.05)$. Analyses were performed using GraphPad Prism 5.0 (GraphPad Software, LaJolla, CA, USA). 


\section{Results and Discussion}

\section{In vitro evaluation of viable cell release from oral live bacterial vaccine formulations using a complete GI model}

Initially we used a complete GI model (Fig. 1) to assess the release of live cells from two oral formulations of attenuated salmonella strains: firstly, the approved oral Typhoid Fever vaccine Vivotif containing dried Salmonella typhi strain Ty21a formulated in enteric coated capsules; and secondly an experimental enteric polymer film laminate (PFL) formulation, previously shown to completely protect dried cells of a live model vaccine (Salmonella Typhimurium strain SL3261) from acid when tested using simple SGF and SIF [25]. Surprisingly, when tested in the complete gastro-small intestine model with complete simulated gastric and intestinal fluids (bioSGF and bioSIF), the PFL released very few cells $\left(\sim 2 \times 10^{7} \mathrm{CFU} / \mathrm{mL}\right)$, and no viable cells were recovered from the Vivotif capsules, (<detection limit of $10^{5} \mathrm{CFU} / \mathrm{mL}$ ) (Fig. 2). After overnight culture, high bacterial cell concentrations of $>10^{10} \mathrm{CFU} / \mathrm{mL}$ for Vivotif and $>10^{12} \mathrm{CFU} / \mathrm{mL}$ for PFL were found (data not shown). The presence of peptone in the bioSIF medium allows cells to replicate within the model, therefore the high cell counts found after overnight incubation indicated that although too few viable cells were released to be detected at 300 minutes, sufficient live cells were released to replicate overnight in the simulated intestinal fluids. This indicates that although inefficient at delivery, simulated GI transit was not totally sterilizing to these two formulations.

The poor viable cell recovery from Vivotif capsules in the gut model is at first sight surprising given this formulation is a widely used and effective vaccine. However this convenient capsule formulation was shown in human trials to be significantly less immunogenic than when the same attenuated strain was administered in a carbonate buffer [8,9], and multiple capsules must be taken on separate days for effective protective immunisation. Although cell recovery in the GI model was poor, live cells were recovered after overnight incubation, indicating that sufficient live cells had been released to replicate in situ. Furthermore, the number of live bacterial cells that must be delivered to the intestine to induce protective immunity in humans is unknown. Therefore it remains plausible that this simple and convenient capsule formulation is inefficient at delivering viable Ty21a bacteria in vivo - yet sufficient viable cells are delivered even with this suboptimal formulation to promote protective immunity in some recipients.

The PFL formulations containing room temperature dried model live bacteria vaccine $S$. Typhimurium SL3261 were previously shown to effectively protect from gastric acid in simple SGF and SIF dissolution tests [17]. In contrast the significant drop in viable cell number when tested in complete simulated gastro-intestinal fluids (BioSGF and BioSIF) in the GI model (Fig. 2) suggested that this formulation, like the Vivotif enteric coated capsules, may also be not optimal for effective delivery of viable cells in vivo. 


\section{Figure 2}

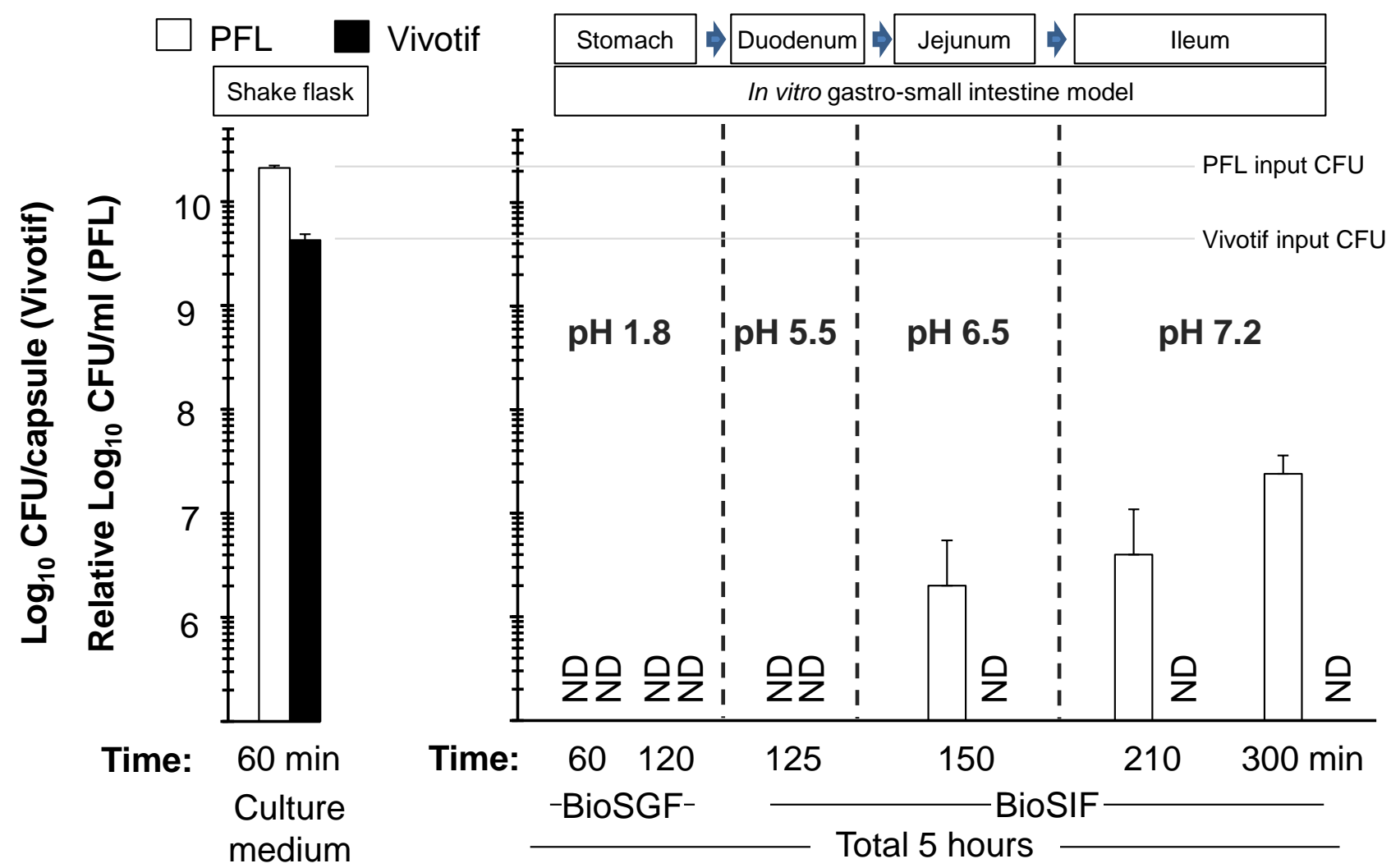

FIGURE 2. In vitro evaluation of live cell release from two oral live bacterial vaccine formulations in a complete gastro small intestine model. Vivotif enteric coated capsules containing dried S. Typhi Ty21a or a prototype oral polymer film laminate (PFL) formulation containing dried cells of the attenuated vaccine S. Typhimurium SL3261 were tested in the GI model by immersion in the dose holder in BioSGF for 2 hours followed by transfer into BioSIF at increasing $\mathrm{pH}$, and viable cell release determined at the indicated timepoints. For comparison, the contents of aseptically opened Vivotif capsules or unformulated polymer films with identical doses of dried SL3261 cells were dispersed directly into culture medium to determine maximal dose of viable cells in each formulation. Viable cell counts are expressed as CFU per capsule for vivotif, or for PFL as CFU/ml normalised to the cell volume prior to drying, to allow comparison with cell density prior to drying and formulation. Each bar represents a single dose with the error bar indicating the standard deviation of 6 replicate cell counts of each sample. Similar viable cell recovery and release kinetics were observed in 3 independent experiments. $\mathrm{ND}=$ not detected, with no colonies detected from undiluted samples, indicating viable cell recovery below a limit of detection of $10^{\wedge} 5 \mathrm{CFU}$ per dose.

No loss of cells was observed when PFL were tested in a simple dissolution medium (SGF followed by $\mathrm{SIF}$ ) in beakers, yet a similar major loss of cell viability was observed when PFL were tested in bioSGF followed by bioSIF in beakers to that observed in the semi-continuous complete gastro small intestinal model (Fig. 2, [17] and data not shown), confirming that the loss in viability could be attributed to the change in dissolution media composition rather than to differences in mixing conditions or vessel size/shape. This suggested that one or more components of the complex bioSIF is toxic to dried vaccine cells formulated in both enteric coated capsules and PFL formulations. 


\section{Impact of simulated fluid composition on cell survival in Vivotif capsules}

To fully understand the reasons for the poor live cell recovery from Vivotif capsules in the GI model, viable cell release from capsules was studied in shaken beakers and the effect of bile and gastric acid were evaluated separately. Surprisingly, when Vivotif capsules were placed into simple SIF or complex BioSIF either directly or after $2 \mathrm{~h}$ of acid challenge (SGF or BioSGF), the maximum viable cell recovery after $3 \mathrm{~h}$ in shaken beakers was $7.6 \times 10^{6} \mathrm{CFU} /$ capsule, in SIF without pre-incubation in acid (Fig 3A). Capsules are loaded with at least $2 \times 10^{9} \mathrm{CFU}$ per capsule, so this represents surprisingly poor viable cell release. Indeed, when dry cell powder was aseptically removed from opened Vivotif capsules and dispersed directly in SIF or culture medium, the expected viable cell numbers were released (Fig. 3B), with $0.8 \times 10^{9} \mathrm{CFU} /$ capsule and $2 \times 10^{9} \mathrm{CFU} /$ capsule released in SIF and culture medium respectively. This suggested that a major cause for low cell recovery from whole capsules is the inefficient release of capsule contents. Although capsules had visibly disintegrated after $3 \mathrm{~h}$ at intestinal $\mathrm{pH}$, a viscous gel was formed from the remains of the capsule shell that could potentially trap many of the bacteria limiting release and dispersal. In addition to inefficient release, significant reduction in viable cell release moving from culture medium to SIF and to BioSIF indicates that dried cells within the capsules are sensitive to the composition of the reconstitution buffer. When dried Vivotif powder was directly exposed to BioSIF, viability rapidly decreased giving a $1 \log \operatorname{loss}$ compared to powder dispersed into SIF, confirming that dried Ty21a cells in Vivotif are bile sensitive (Fig 3a). Similar loss in cell viability was observed when the Vivotif capsule content was tested in SIF with $1 \%$ bile addition, confirming that the major difference between SIF and BioSIF can be attributed to bile (rather than enzymes or differences in salt). The loss of viability can be attributed to transient bile sensitivity of dried cells rather than any intrinsic sensitivity of Ty21a to bilesince after a 30 minute recovery period in culture medium, addition of $1 \%$ bile gave no reduction in cell viability (Fig. 3b), confirming that as expected $S$. typhi Ty21a cells are not intrinsically sensitive to bile. The high bile sensitivity of lyophilized Ty21a cells is consistent with previous studies of both thermostabilised dried Gram negative LBV and freeze-dried Gram positive probiotics [13, 14].

When enteric coated Vivotif capsules were exposed to BioSIF either directly, or after $2 \mathrm{~h}$ in acid, viability rapidly dropped below the limit of detection $\left(10^{5} \mathrm{CFU} / \mathrm{mL}\right)$, representing more than a $10^{4}$ fold loss. In contrast, when Vivotif capsule was placed directly into SIF, significant numbers of viable cells were recovered $\left(\sim 10^{7} \mathrm{CFU} / \mathrm{mL}\right)$. When the capsule was transferred into SIF following $2 \mathrm{~h}$ in SGF, cell survival was reduced with $\sim 1 \log$ loss in viability attributed to immersion in acid, demonstrating that although the capsule enteric coating provides significant protection from acid and prevents release at gastric $\mathrm{pH}$, some acid penetration occurred, suggesting the enteric coating on this formulation may not provide complete gastric acid resistance.

In summary, the failure to recover viable Ty21a cells from Vivotif capsules in the complete GI model (Fig 2) can be attributed to a combination of incomplete release of live cell contents (Fig. 3a vs b), incomplete protection from gastric acid (Fig 3a), combined with sensitivity of the dried cells to bile after release in BioSIF (Fig. 3a \& b). 


\section{Figure 3}

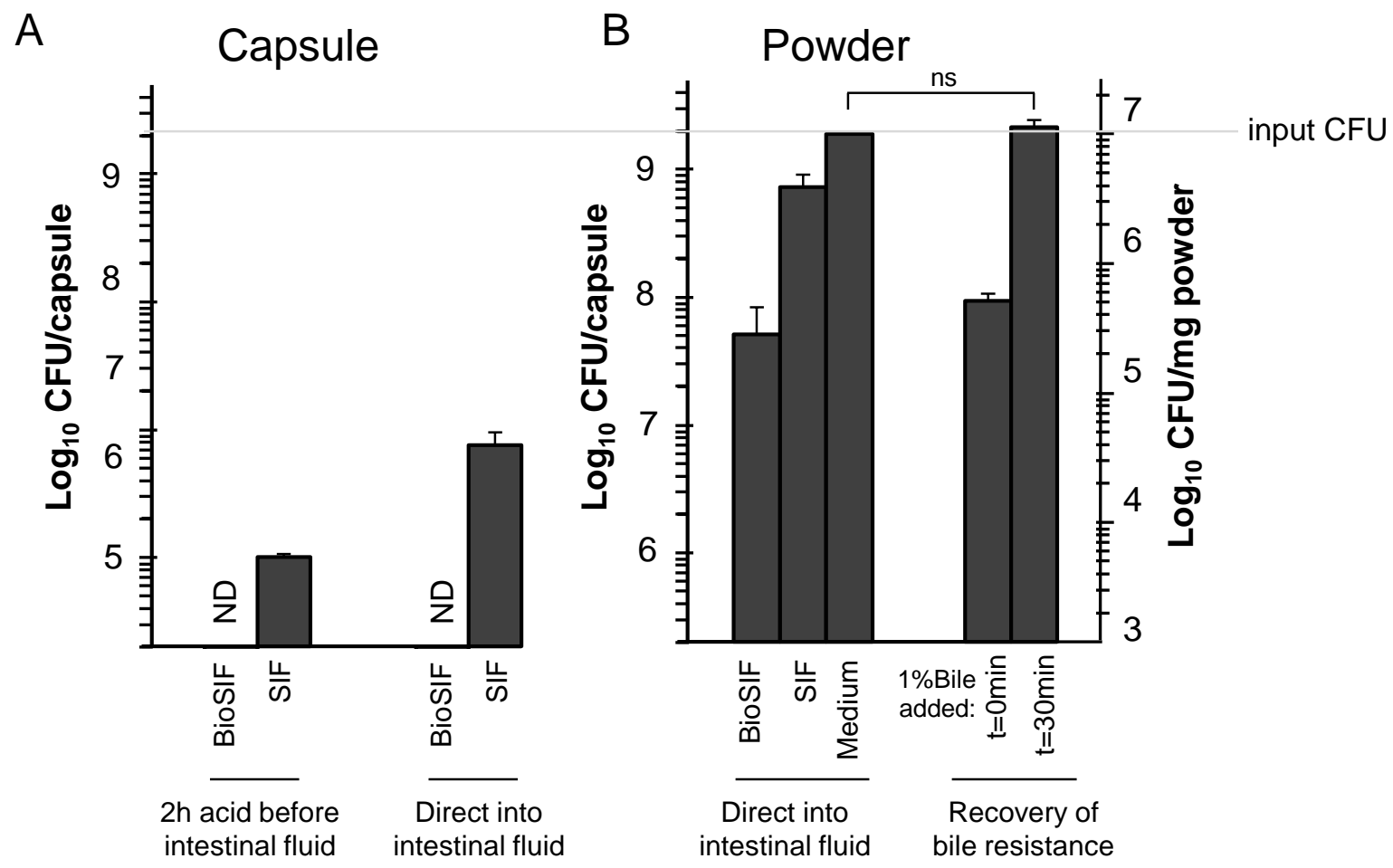

FIGURE 3. Characterizing live cell release from Vivotif capsules and bile sensitivity of dried Ty21a cells. A Release of viable $S$. Typhi Ty21a cells from enteric coated Vivotif capsules was evaluated after $3 \mathrm{~h}$ incubation in $100 \mathrm{~mL}$ of simple (SIF) or complete (BioSIF) simulated intestinal fluid compositions in beakers with orbital shaking, either directly added or following $2 \mathrm{~h}$ incubation in the indicated simulated gastric fluid. Viable cell counts were expressed as CFU/capsule. B The sensitivity of dried cells from Vivotif capsules was tested at $1 \mathrm{~h}$ after dispersal of samples of approximately $10 \mathrm{mg}$ powder into SIF or BioSIF and compared to powder dispersed in culture medium. To demonstrate that the observed sensitivity to bile of dried Ty21a cells was reversible, $10 \mathrm{mg}$ samples were either dispersed in culture medium for 30 minutes followed by addition of bile dissolved in SIF to give a final concentration of $1 \%$ (bile added $t=30$ ), or directly dispersed in a mixture of culture medium and SIF with bile at $1 \%$ (bile added $\mathrm{t}=0 \mathrm{~min}$ ), followed by evaluation of viable cell counts at $1 \mathrm{~h}$. Viable cell numbers were calculated and can be evaluated on two axes: either as CFU/capsule (left axis, for comparison with part A) or as CFU/mg dried cell powder (right axis). Capsules contained 180mg dried cell powder. Data are representative of at least 3 repeat experiments.

\section{Developing bile resistant PFL incorporating bile adsorbent resin}

The surprisingly poor delivery of viable bacteria from enteric coated capsules suggests that improved formulations for oral delivery of LBV are required. Previous studies using tablets and capsules showed that transiently bile sensitive dried cells can be protected with bile adsorbing resins $[12,24]$. Having previously established that drying live bacteria directly onto enteric polymer films and formulation into PFL provided effective protection from acid and controllable release kinetics [17], we explored here whether bile adsorbing resins can likewise be incorporated into this simple novel formulation to protect dried cells from bile. Four pilot formulations were produced and evaluated in simple release studies comprising incubation for $2 \mathrm{~h}$ in SGF or BioSGF in beakers, then transfer into beakers of either SIF or BioSIF at pH 6.8, with sampling after $2 \mathrm{~h}$ in acid and at $1 \mathrm{~h}$ and $3 \mathrm{~h}$ at intestinal 
$\mathrm{pH}$. The pilot formulations included: an unmodified control PFL made from laminated enteric polymer alone; formulation BR-PFL B with a single layer of Eudragit cast from polymer solution mixed with bile adsorbing resin; formulation BR-PFL C comprising two polymer layers, with the external layer cast from enteric polymer alone and an internal layer cast from enteric polymer mixed with bile adsorbing resin; and BR-PFL D with three polymer layers, with a central layer cast from enteric polymer mixed with bile adsorbing resin surrounded with (Fig. 4 top).

The first and simplest prototype formulation BR-PFL B showed high cell losses after immersion in acid, likely caused by acid penetration through the enteric film during incubation in SGF/BioSGF caused by porous particles of bile adsorbing resin embedded in the film (Fig. 4). This formulation was not selected for further tests, and subsequent BR-PFL prototypes were designed to overcome the porosity of films cast from enteric polymer mixed with bile adsorbing resins.

BR-PFL C and BR-PFL D both provided effective protection from acid (Fig. 4). Both had an outer polymer film layer cast from Eudragit alone that completely protected the PFL from acid, and the bile adsorbing resin was incorporated into an inner layer. BR-PFL D had a third additional thin inner layer of Eudragit film onto which the cells were dried. Like PFL, excellent cell recovery of $>10^{9} \mathrm{CFU} / \mathrm{ml}$ after $2 \mathrm{~h}$ in SGF and $3 \mathrm{~h}$ in SIF indicated effective acid protection, with identical cell recovery to replicate samples directly dispersed in SIF without lamination indicating no loss in viability during $2 \mathrm{~h}$ in SGF (Fig. 4b). When tested in BioSIF and BioSGF, far higher viable cell numbers were recovered from BR-PFL C and BR-PFL D compared to the PFL without bile adsorbent resin. The PFL alone provided some protection from bile containing Bio-SIF, with $1.5 \log$ higher cell recovery compared to that observed in non-laminated dried cells exposed to $1 \%$ bile, suggesting that cast films of Eudragit can provide protection from bile to dried cells, as observed previously with HPMC capsule shells [24]. However, the best recovery, with > 2 log higher recovery than direct exposure to $1 \%$ bile, was observed with BR-PFL C and BR-PFL D (Fig. 4), demonstrating that enteric polymer films incorporating bile adsorbing resins can protect dried LBV cells from both bile and acid.

Although different release kinetics were observed depending on the lamination method (and simulated intestinal fluid composition), all formulations released maximal viable cells by $3 \mathrm{~h}$ in BioSIF following $2 \mathrm{~h}$ in BioSGF. BR-PFL D had slower release kinetics in SIF, likely due to the increased thickness of the three layered system which takes longer to swell, dissolve and fully release contents at elevated $\mathrm{pH}$. All other formulations had more rapid release kinetics in SIF - with complete release by 1 $\mathrm{h}$ - than in BioSIF where $3 \mathrm{~h}$ was required for total release, indicating that fluid composition not only affects LBV viability but also release kinetics. This may be related to buffer concentration, with SIF having a $30 \%$ higher buffer concentration than BioSIF, consistent with prior study demonstrating that release from enteric coated dosage forms at small intestinal $\mathrm{pHs}$ is buffer concentration dependent [25].

In conclusion, using laminated multiple layer films cast from $\mathrm{pH}$ responsive enteric polymer plus bile adsorbing resins we produced a simple oral formulation that protects dried LBV from both acid and bile and allows release of high numbers of viable cells with release kinetics controlled by film thickness. 


\section{Figure 4}
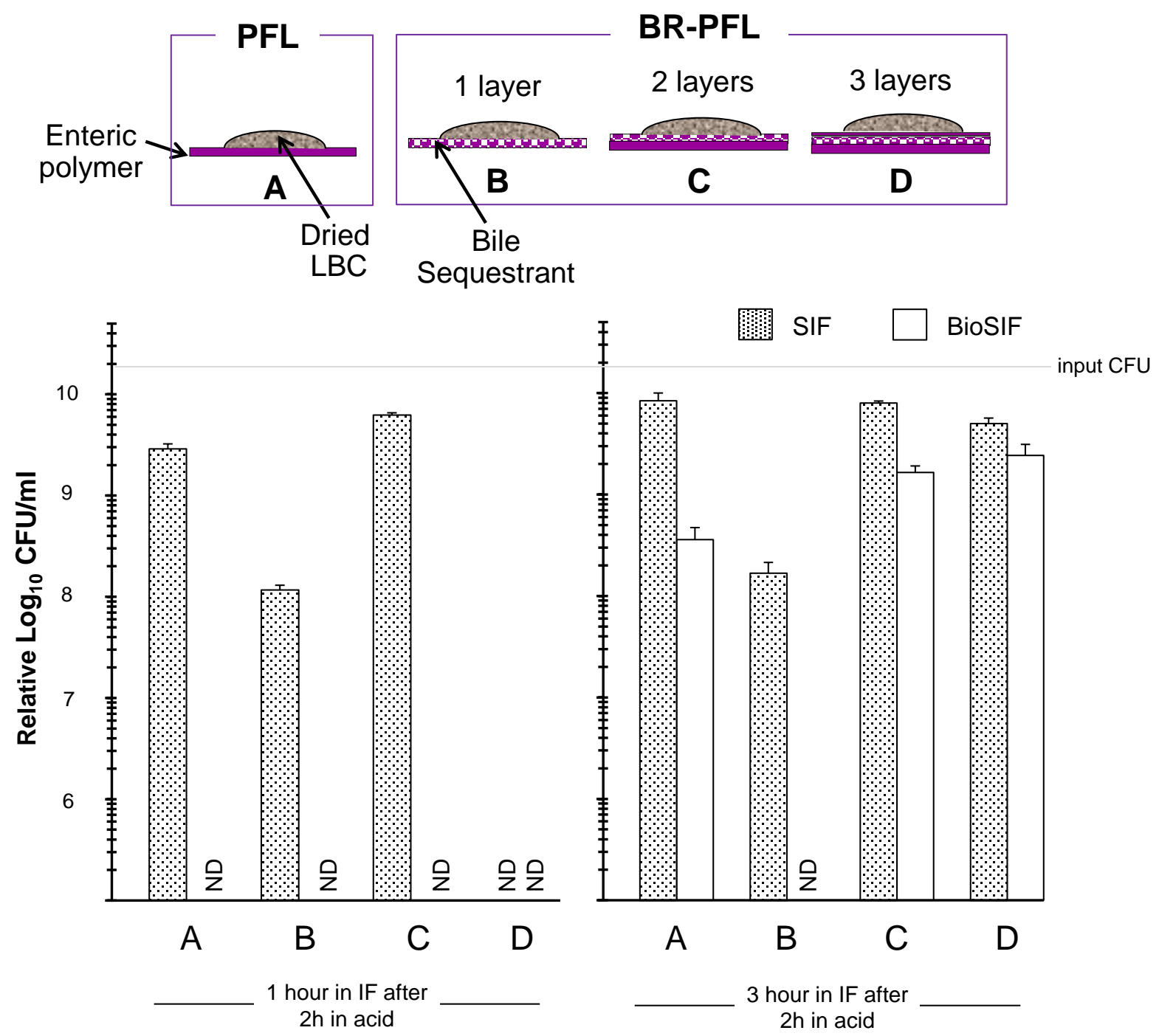

FIGURE 4. Developing bile resistant polymer film laminate formulations. $S$. Typhimurium SL3261 cells were dried onto cast polymer films and made into either PFL (A) or prototype bile resistant PFL (BR-PFL) with the bile adsorbing resin cholestyramine incorporated into different polymer layers as illustrated in the top panel (formulations $\mathrm{B}, \mathrm{C}$, and $\mathrm{D}$ ). The acid and bile resistance of the novel PFL formulations was tested in simulated gastrointestinal fluids by immersion in acid for 2 hours followed by transfer into either simple SIF or complete BioSIF for 3 hours. Cell viability was tested after $1 \mathrm{~h}$ and $3 \mathrm{~h}$ in the intestinal fluid, and cell counts expressed relative to the volume initially dried into each formulation (i.e. relative $\mathrm{CFU} / \mathrm{ml}$ ). Each bar represents a single formulation with error bars indicating standard deviation of 6 replicate cell counts. Similar viable LBC recovery was observed in 3 different experiments comparing different BR-PFL formulations. $\mathrm{ND}=$ not detected, with no colonies detected from undiluted samples, indicating viable cell recovery below a limit of detection of $10^{\wedge} 5 \mathrm{CFU}$ per dose.

\section{BR-PFL oral formulation for controlled delivery of vaccine in in vitro upper GI model}

Having established in pilot tests that version D of the BR-PFL provided effective acid and bile resistance in simple shaken beaker studies, this enteric oral formulation was then tested in the complete multi-stage in vitro GI model (Fig. 1) to evaluate live cell delivery of LBV during simulated gastrointestinal transit. BR-PFL containing dried $S$. typhimurium SL3261 were inserted in customized holders, and placed into vessel 1- stomach for $2 \mathrm{~h}$, then transferred to vessel 2 - duodenum for 5 
minutes, then transferred to vessel 3 - jejunum for 25 min and finally transferred to vessel 4 - ileum for $2.5 \mathrm{~h}$, with a complete transit time of $5 \mathrm{~h}$. Samples to determine viability were taken after $2 \mathrm{~h}$ in the gastric stage and the small intestine stages were sampled at $2 \mathrm{~h} 5 \mathrm{~min}, 2.5 \mathrm{~h}, 3.5 \mathrm{~h}$ and $5 \mathrm{~h}$. As expected from the beaker studies, when BR-PFL D was incubated in the initial BioSGF stage, the formulation remained intact and no cells were recovered. After transfer to the intestinal stages, high numbers of viable cells were released (Fig. 5). Viable cell release plateaued after only 60 minutes at pH 7.2, corresponding to a gastrointestinal transit of $3.5 \mathrm{~h}$. When compared to replicate samples of cells dried onto enteric polymer films dispersed directly in SIF after drying, less than $0.5 \log$ loss in viability was observed, suggesting the BR-PFL is effective at blocking both gastric acid and intestinal bile toxicity, and therefore highly suited for efficient oral delivery of therapeutic live bacterial cells.

\section{Figure 5}

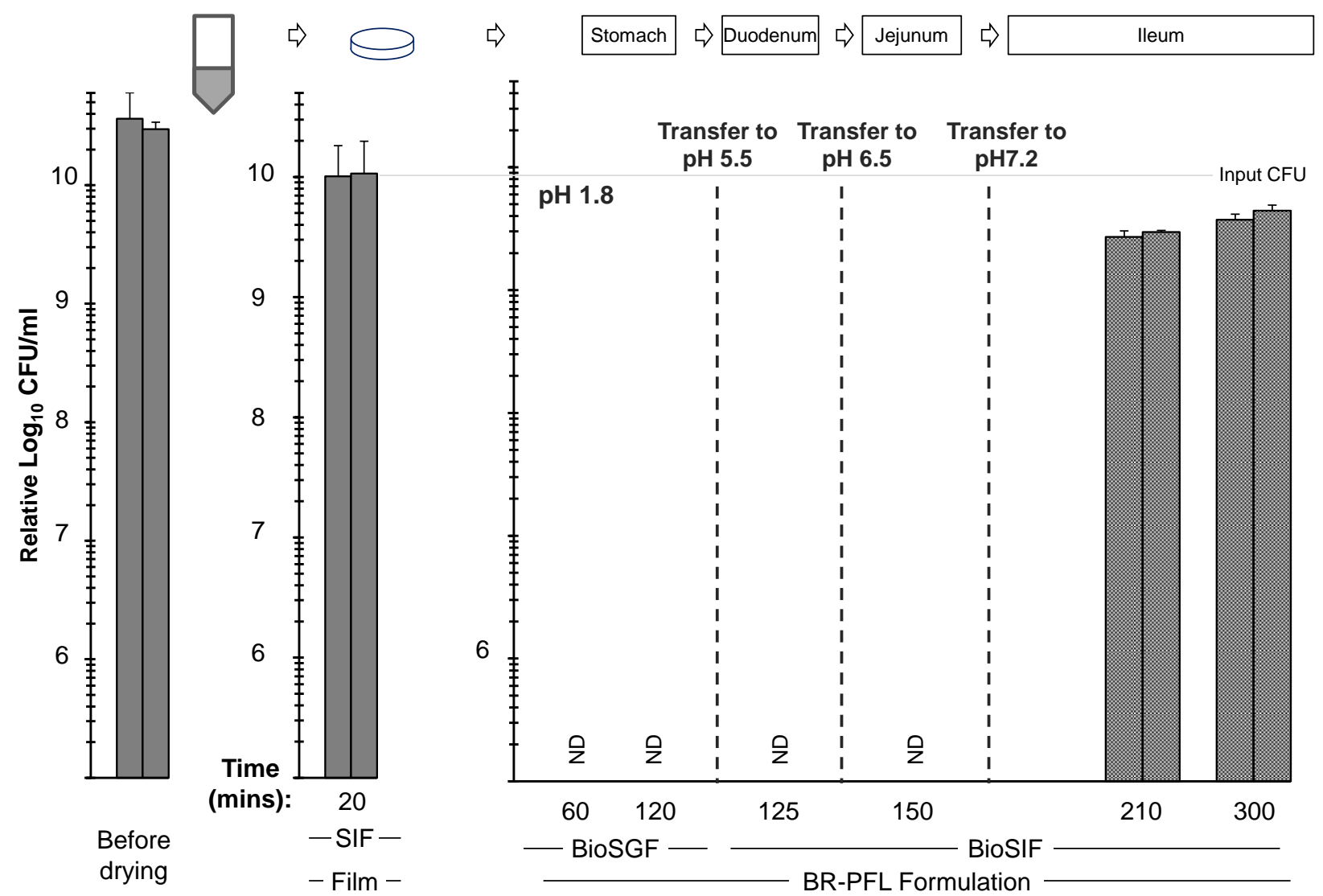

FIGURE 5. In vitro evaluation of prototype Bile Resistant Polymer Film Laminate (BR-PFL) in the gastro small intestine model demonstrating effective protection and release of dried live cells in intestinal conditions. $S$.

Typhimurium SL3261 cells were dried onto triple layered films of enteric polymer and bile adsorbant resin, and laminated into BR-PFL formulations. The viable cell count prior to drying and post-drying viability of non-laminated samples were measured (left). Duplicate BS-PFL formulations were placed into a dose holder and sequentially immersed in the four stages, starting with BioSGF for 2 hours followed by transfer into BioSIF at increasing $\mathrm{pH}$, and viable cell release sampled at the indicated timepoints. Viable cell counts are expressed normalised to the initial volume of cell slurry prior to drying to allow simple comparison in each stage. The prototype BR-PFL contained $10 \mu \mathrm{L}$ of cells prior to drying, thus each dose released $4 \times 10^{7} \mathrm{CFU}$. Each bar represents a single BS-PFL formulation with the error bar indicating the standard deviation of 6 replicate cell counts of each sample. Similar viable cell recovery and release kinetics were observed in 3 independent experiments. $\mathrm{ND}=$ not detected, with no colonies detected from undiluted samples, indicating viable cell recovery below a limit of detection of $10^{\wedge} 5 \mathrm{CFU}$ per dose. 


\section{Conclusion}

This study illustrates the importance of using in vitro models that closely mimic human GI conditions for studying the formulation and release of complex biopharmaceuticals such as live bacterial cells. Significant differences in cell viability and kinetics of release were observed when experimental formulations were tested in a complex gastro small intestine model compared to conventional dissolution apparatus, reinforcing the importance of matching fluid composition of GI models to in vivo conditions when testing formulations. Both oral vaccine formulations tested - both conventional Vivotif capsules and the novel PFL - showed high losses in viable cells numbers during simulated gastrointestinal transit even though both contained high cell numbers of dried cells that could be released in simple dissolution media such as USP SIF. Using a gut model system it was possible to develop an improved PFL oral formulation for live vaccine bacterial delivery to the distal small intestine, by incorporating additional excipients to protect dried live cells from bile. The optimized BRPFL oral formulation gave protection from both acid and bile and allows controlled enteric delivery of a dose of $4 \times 10^{7} \mathrm{CFU}$ of a model attenuated vaccine, with higher doses possible by increasing the quantity of dried cells in the formulation. Although in vitro modelling remains the best way to understand and control both the effect of food and nutritional supplements on gut health, but also the fate of orally administered drugs in the GI tract, further studies of novel live bacterial vaccines formulations such as BR-PFL are needed to determine in vivo cell delivery performance and ultimate immunogenicity and efficacy.

\section{ACKNOWLEDGMENTS}

We are grateful to the University of Reading and Reading School of Pharmacy for studentship funding to JB. We acknowledge the Chemical Analysis Facility at the University of Reading for the use of equipment and expertise.

\section{REFERENCES}

1. Levine, M.M., Enteric infections and the vaccines to counter them: future directions. Vaccine, 2006. 24(18): p. 3865-3873.

2. Medina, E. and C.A. Guzmán, Use of live bacterial vaccine vectors for antigen delivery: potential and limitations. Vaccine, 2001. 19(13-14): p. 1573-1580.

3. Duan, F., K.L. Curtis, and J.C. March, Secretion of insulinotropic proteins by commensal bacteria: rewiring the gut to treat diabetes. Appl Environ Microbiol, 2008. 74(23): p. 7437-8.

4. Granato, D., et al., Functional Foods and Nondairy Probiotic Food Development: Trends, Concepts, and Products. Comprehensive Reviews in Food Science and Food Safety, 2010. 9(3): p. 292-302.

5. $\quad$ Morgan, C., et al., Preservation of micro-organisms by drying; a review. Journal of Microbiological Methods, 2006. 66(2): p. 183-193.

6. Ratanasuwan, W., et al., Peru-15 (Choleragarde $\left.{ }^{\circledR}\right)$, a live attenuated oral cholera vaccine, is safe and immunogenic in human immunodeficiency virus (HIV)-seropositive adults in Thailand. Vaccine, 2015. 33(38): p. 4820-4826.

7. Chen, W.H., et al., Safety and Immunogenicity of Single-Dose Live Oral Cholera Vaccine Strain CVD 103-HgR, Prepared from New Master and Working Cell Banks. Clinical and Vaccine Immunology, 2014. 21(1): p. 66-73.

8. Levine, M.M., et al., Duration of efficacy of Ty21a, attenuated Salmonella typhi live oral vaccine. Vaccine, 1999. 17 Suppl 2: p. S22-7. 
9. Levine, M.M., et al., Comparison of enteric-coated capsules and liquid formulation of Ty21a typhoid vaccine in randomised controlled field trial. Lancet, 1990. 336(8720): p. 891-4.

10. Brenneman, K.E., et al., Use of Ensure $(R)$ nutrition shakes as an alternative formulation method for live recombinant Attenuated Salmonella Typhi vaccines. BMC Microbiol, 2015. 15: p. 76.

11. Sander, L.E., et al., Detection of prokaryotic $m R N A$ signifies microbial viability and promotes immunity. Nature, 2011. 474(7351): p. 385-389.

12. Edwards, A.D. and N.K.H. Slater, Protection of live bacteria from bile acid toxicity using bile acid adsorbing resins. Vaccine, 2009. 27(29): p. 3897-3903.

13. Mahbubani, K.T., N.K.H. Slater, and A.D. Edwards, Protection of dried probiotic bacteria from bile using bile adsorbent resins. New Biotechnology, 2014. 31(1): p. 69-72.

14. Edwards, A.D. and N.K.H. Slater, Formulation of a live bacterial vaccine for stable room temperature storage results in loss of acid, bile and bile salt resistance. Vaccine, 2008. 26(45): p. 5675-5678.

15. Siepmann, F., et al., Polymer blends for controlled release coatings. Journal of Controlled Release, 2008. 125(1): p. 1-15.

16. Cook, M.T., et al., Microencapsulation of probiotics for gastrointestinal delivery. Journal of Controlled Release, 2012. 162(1): p. 56-67.

17. de Barros, J.M., et al., A laminated polymer film formulation for enteric delivery of live vaccine and probiotic bacteria. J Pharm Sci, 2014. 103(7): p. 2022-32.

18. Mainville, I., Y. Arcand, and E.R. Farnworth, A dynamic model that simulates the human upper gastrointestinal tract for the study of probiotics. International Journal of Food Microbiology, 2005. 99(3): p. 287-296.

19. Macfarlane, G.T. and S. Macfarlane, Models for intestinal fermentation: association between food components, delivery systems, bioavailability and functional interactions in the gut. Curr Opin Biotechnol, 2007. 18(2): p. 156-62.

20. Macfarlane, G.T., S. Macfarlane, and G.R. Gibson, Validation of a Three-Stage Compound Continuous Culture System for Investigating the Effect of Retention Time on the Ecology and Metabolism of Bacteria in the Human Colon. Microb Ecol, 1998. 35(2): p. 180-7.

21. MINEKUS, et al., A multicompartmental dynamic computer-controlled model simulating the stomach and small intestine. Vol. 23. 1995, Nottingham, ROYAUME-UNI: Fund for the Replacement of Animals in Medical Experiments.

22. Molly, K., M. Vande Woestyne, and W. Verstraete, Development of a 5-step multi-chamber reactor as a simulation of the human intestinal microbial ecosystem. Applied Microbiology and Biotechnology, 1993. 39(2): p. 254-258.

23. Sannasiddappa, T.H., et al., The Influence of $<$ italic $>$ Staphylococcus aureus $</$ italic $>$ on Gut Microbial Ecology in an <italic > In Vitro</italic $>$ Continuous Culture Human Colonic Model System. PLoS ONE, 2011. 6(8): p. e23227.

24. Edwards, A.D., et al., Optimal protection of stabilised dry live bacteria from bile toxicity in oral dosage forms by bile acid adsorbent resins. Chemical Engineering Science, 2010. 65(16): p. 4844-4854.

25. Ozturk, S.S., et al., Kinetics of release from enteric-coated tablets. Pharm Res, 1988. 5(9): p. 550-65.

\section{Conflicts of interest statement}

Conflicts of interest: None 